\title{
Vocabulary Memorization Strategies among Arab Postgraduate English Foreign Language Learners
}

\author{
Fouad Hussein Al-Qaysi (Corresponding author) \\ College of Education, Tikrit University, Iraq \\ E-mail: fhn58@yahoo.com \\ Ahmad Affendi Shabdin \\ College of Art and sciences, University Utara Malaysia, Malaysia \\ E-mail: affandi@uum.edu.my
}

Doi:10.7575/aiac.alls.v.7n.5p.184

URL: http://dx.doi.org/10.7575/aiac.alls.v.7n.5p.184
Received: 13/06/2016

Accepted: 27/08/2016

\begin{abstract}
Many studies have investigated vocabulary memorization strategies in the EFL context, but few researches have been conducted on the types of memorization strategies used by the Arab students in Malaysia. Thus, this study investigates the types of vocabulary memorization strategies employed by the Arab students in the Intensive English course at UUM. The aims of the study were to investigate vocabulary memorization strategies used by the Arab students and to examine the most and the least frequent strategies employed by the Arab students in learning and memorizing vocabulary. The samples of the study were 65 postgraduate Arab students from different colleges; COB, CAS and COLGIS at UUM. One instrument was used in this study, which is a questionnaire. The questionnaire was adapted from Li (2004) which is based on Oxford's taxonomy (2003). The results indicated that the Arab students use different strategies in learning and memorizing vocabulary. Reviewing well strategies were found to be the most preferred strategies in contrast with Employing actions which was found to be as the least category employed by the Arab students. Writing words repeatedly a strategy from Reviewing well category was found to be the most strategy used by the Arab students in the Intensive English course while the Associate sounds of words with similar English from Employing actions category was the least strategy used by them. The findings revealed that Arab students see vocabulary memorization strategies help them in learning the English language and consistent with their cultural and educational background.
\end{abstract}

Keywords: vocabulary memorization strategies, UUM, Intensive English course, Arab students

\section{Introduction}

The recognition of the role of vocabulary in learning languages has continued to grow in the last years, because of its importance in learning the second/foreign language. Many strategies are distinguished and established lately, when researchers and teachers make their goals in learning the languages to be easier, faster, enjoyable, and more selfdescribed (Oanh and Hien, 2006). Vocabulary is a very important component of language learning and the development of learning vocabulary is generally considered as a decisive part of language competence by the researchers of both first and second language (Heidari, Karimi and Imani, 2012). Since memorizing vocabulary plays a major role in the process of vocabulary learning, different strategies in learning and memorizing vocabularies are established by researchers in order to facilitate learning and memorizing the vocabulary. Memorization is the most accessible means of possessing knowledge and it is also a crucial characteristic of knowledgeable and intellectual personalities (Yusuf, 2010). Some learners use memorization as their learning styles in learning language and see this method as an effective tool in mastering the new knowledge. Ellis (1994) and Fan (2003) have indicated that learning environments and cultures can affect the selection of learning and memorizing vocabulary strategies. Therefore, it can be seen that most of EFL learners use memorization strategies as their learning style in learning vocabulary and according to Oanh and Hien (2006) memorization is seen to be one of the crucial methods in language learning as it assists EFL learners in learning and using the English language.

Moreover, nowadays it is observed that more and more scientific vocabulary books, which are published in different countries, focus on different memorization strategies, such as bilingual word list, sentences used in specific situations and places, flash card, and keywords strategies, in order to help students in memorizing new words. Also, English textbooks of some EFL countries are revised in order to add some frequently used sentences and words in different texts or even in one text. After reading the text, the vocabulary exercises are also designed to be installed deeply in their memory. This further reflects the universality as well as the importance of memorization in EFL context. (Essays, UK, 2013). 
Retention and recalling of vocabulary items when needed is deemed as the biggest challenge for the ESL and EFL learners alike (Sinhaneti and Kyaw, 2012). Most of the EFL learners have difficulty in remembering the words that they previously learned and according to $\mathrm{Gu}$ (2003), the most important issue in learning the vocabulary is memorizing since vocabulary learning is a memory problem. Although there are many reasons responsible for the problem of remembering, the main cause of this problem is the strategies and methods of acquiring the word meaning. Asgari and Mustapha (2011) have noted that by using different strategies, the learning process becomes more efficient and effective, and the learners become more proficient in learning the second language. Therefore, to help the learners enhance their vocabulary ability and overcome the difficulties of memorizing vocabulary, they should be taught different strategies in the process of learning and memorizing the vocabulary. In addition to that, these strategies should be taught in a way that the students will be capable of recalling the learned words easily, and knowing how and when to use these words. Many studies have been conducted to investigate memorization strategies and their effects on EFL learners, such as Ghorbani and Riabi (2011) in Iran, Oanh and Hien (2006) in Vietnam, Nemati (2009) in India and Yang and Dai (2011) in China, and Yusuf (2010) in Malaysia. As far as language learning is concerned, limited studies have been conducted to investigate the vocabulary memorization strategies among Arab learners at UUM (Universiti Utara Malaysia). Thus, this study aims to examine the vocabulary memorization strategies employed by Arab postgraduate EFL learners in the Intensive English course at UUM. Therefore the objectives of the study are:

1- To examine the vocabulary memorization strategies which are used by the Arab students in the Intensive English course in UUM.

2- To discover the most and the least frequent memorization strategies used by the Arab students in the Intensive English course in UUM.

Based on these objectives, this study sought to find answers to the following questions:

1- What are the types of vocabulary memorization strategies employed by the Arab students in the Intensive English course?

2- What are the most and the least frequent memorization strategies used by the Arab students in the Intensive English course?

\section{Literature Review}

\subsection{Vocabulary}

Vocabulary as widely acknowledged is the most significant building block of teaching and learning foreign language in the recent age. According to Read (2000, p. 1), vocabulary are words which form the foundation of language and represent the units of meaning out of which paragraphs, sentences and entire text are formulated. Graves (2000) defines vocabulary as a set of word that is relevant to a specific individual or to a branch of knowledge. The language vocabulary importantly encompasses language lexicon of words and expressions. While vocabulary according to Gardener (2013) is considered from a wider perspective since it goes beyond structuring of a language alone but covers the meaning of words, how the words are discovered, used, stored, the relationship that exists between phrases and words as well as their classifications. Therefore, vocabulary is very important in learning any language since it has been found that vocabulary has the distinctive power of enriching the integrative language skills such as listening, speaking, reading and writing.

\subsection{Importance of Vocabulary Learning}

Among the language skills, vocabulary is widely acknowledged to be very important in English learning since without it meaningful communication is impossible. It has been established that students who have adequate knowledge about words in most of EFL contexts are always successful in learning (Alemi and Tayebi, 2011).Vocabulary learning is an important process that ESL/EFL learners must pass through in order to acquire adeptness and competence in their chosen language, since word power has been proven to be capable of facilitating fluency in speaking and effectiveness in writing. In addition, it has also been found that vocabulary has the distinctive power of enriching the integrative language skills such as listening, speaking, reading and writing. Widdowson (1989) and McKeown (2002) argue that the knowledge of vocabulary is the foundation of a language understanding and use. In addition, Barra (2005) suggested that to successfully understand a text the students must possess enough word knowledge. In essence, the level of understanding of a language will depend on the quantity of words that learners know in that language. Importantly too, learners must have sufficient word knowledge to comprehend what they read. Students can comprehend the message of the writer only if they know the meaning of words that the users used in a text.

\subsection{Memorization and Vocabulary Learning}

A number of theorists and researchers have recognized the importance of vocabulary knowledge in process of learning foreign or second language. Various strategies and approaches, practices and techniques have been introduced (Hatch and Brown, 1995). According to Nation (2001) the vocabulary learning strategies are critically regarded as a part of language learning strategy and part of general learning strategies. Schmitt (2000) while supporting this position asserts that the field of vocabulary learning strategies has become very important and has been able to attract the attention of foreign or second language learning experts. Researchers of foreign and second language have been trying to make classification for the vocabulary learning strategies employed by the foreign and second language learners such as (Cohen, 1998; Ellis, 1994; Gu \& Johnson, 1996; Nation, 2001; O'Malley \& Chamot, 1990; Oxford 1990; Lee \& Oxford, 2008; Rubin, 1981; Stern, 1983; Schmitt, 1997; Tarone, 1981). 
From foreign language learning context, memorization is the most commonly used method by EFL learners to acquire or learn vocabulary, structure and language in general. The role of memorization strategies to assist learners to commit new words into memory in the learning process cannot be over-emphasized. By definition, many definitions have been found for the memorization of the literature and various dictionaries. It was found out in studies conducted by Richards, Platt and Platt (1992, p 226) that memorizing is the establishment of the information in memory. The term 'memorizing' normally refers to the conscious procedures. This ensures the fact that the learners do employ the memorization consciously and often think of the memorization process when they are adopted for learning. Another definition clarified by Oxford Advanced Learner's Dictionary (2005) sees "Memorizing is to learn something carefully so that you can remember it exactly." Memorizing technique is equivalent to a description of mental learning strategy called rehearsal (O'Malley and Chamot, 1990). It was pointed out by Wenden and Rubin (1987) that memorization involves strategies designed to facilitate the storage and retrieval of language and this explains the use of some strategies, such as drill and repetition, which used as same as memorization strategies (Wenden and Rubin, 1987 p: 24).

Arguments are bound in literature as regards which strategies should be listed under which category headings. For example, repetition is categorized under the memorization by Rubin (1981), Grains and Redman (1986) and Purpura (1994) whereas it was classified as a cognitive strategy by other studies (O'Malleyet. al, 1985; Oxford, 1990; Schmitt, 1997). However, Oxford (1990) states that a good strategy must be positive and helpful for a given learner by meeting the conditions as followed: (a) relating well to the L2 task at hand, (b) fitting the particular students' learning style preferences to one or another, and (c) linking the strategy effectively with other related strategies.

Oxford's study (2003) assigns strategies into two which are: direct and indirect strategies. These strategies are further subdivided into six groups such as memory, cognitive and compensation for direct strategies, and metacognitive, affective and social for indirect strategies. In view of the fact that this study focuses on the memorization strategies, only memory strategies will be reviewed in depth. Based on Oxford (2003) memory strategies are divided into four sets which are:

1- Creating Mental Linkages (CML): this is categorized into three strategies: namely1) grouping which consists of classifying, and reclassifying language material into meaningful sub-units; b) associating/elaborating which mostly associate new language information to existing ones already stored in the memory; and c) placing of new words into a context which focuses on using a word or phrase in a meaningful sentence, the translation equivalents, conversation or story so as to remember it.

2- Applying Images and Sounds (AIS): a total of four main strategies are included under images and sounds. The use of imagery which associates new language knowledge to concepts in memory through visual imagery that is meaningful, either by depicting it in the mind or actual drawing; b) semantic mapping include arrangement of words into a picture or diagram; c) use of keywords that is done through remembering a new word by use of auditory or visual links. While doing this, it is important to initially identify familiar words in one's own language that sounds like the new words.

3- Reviewing Well (RW): this involves reviewing the words learnt carefully at regular intervals. For instance a learner may choose to review words so far learnt initially at 10 minutes interval after the time of learning the words, this can be increased to 20 minutes and hourly later and so on to assess the remembrance of the new the new target language words.

4- Employing Actions (EA): under this there are two strategies in this set: a) using sensation or physical response. While using physical response a learner acts out the new expression like going to the door, and b) involves the use of mechanical techniques by means of creative but still tangible techniques. A good example can be writing new words on cards with the new word written on one side and its definition on the other side.

The taxonomy suggested by Oxford (2003) has enjoyed wide acceptance. In recognition of the popularity of Oxford's taxonomy, Schmitt (1997, p. 205), remarks it as the more established system of classification which best capture and organize the varied strategies of learning vocabulary. Also, Dornyei (2007) emphasized the importance of these strategies and he added that the compatibility would be important if some changes were made. As the Arab students are still using vocabulary memorization strategies Thus, Oxford's vocabulary learning strategies are assumed to be commonly appropriate categorization for the present study. The reasons for that emanated form, because it assists recalling of words through some level of language manipulation (Schmitt 1997). As such, the study would like to improve the memorization strategies used by the Arab students whose foreign language proficiency is generally seen as low (as evidenced in their ELPT score in English).

\section{Methodology}

The purpose of the current study is to examine vocabulary memorization strategies used by the Arab students in the Intensive English course, and to find out the most, least strategies frequency used. Thus, this research aims to design a descriptive survey study by using quantitative approach. According to Creswell (2012, p. 376) we "use survey research to determine individual opinions". The survey studies are designed in order to process a large data statistically when these data are needed to be researched.

\subsection{The Participants}

The study involved 81 students who were the international students in the Intensive English course representing the population of the study. Whereas the sample, (all Arab students) in the Intensive English course were (69) EFL Arab learners. Only (65) students participated in the study while four students did not attend the classes. The participants 
involved male and female and they were from the following colleges of Utara University Malaysia: College of Arts and Science (CAS), College of Business management (COB), and College of Law, Government and International Studies (COLGIS).

Table 1.Background of the Participants in the Study.

\begin{tabular}{cc}
\hline Colleges & No of Students \\
\hline CAS & 31 \\
COB & 29 \\
COLGIS & 5 \\
Total & 65 \\
\hline
\end{tabular}

Table 1 shows the number of the sample according to their colleges in UUM in the Intensive English course. Most of the students were from CAS and COB colleges while only five students were from COLGIS college. All the participants were from Arab countries and their native language is Arabic.

\subsection{Instrument}

This study used one research instrument to collect data from the students which is a questionnaire. A written vocabulary memorization strategies questionnaire was adapted from Sinhaneti and Kyaw (2012) which is actually based on the studies of Li (2004) and Oxford (2003). The questionnaire was used as the main instrument to identify the vocabulary memorization strategies (patterns and preferences) used by the participants. According to Nunan (1992, p: 231) “a questionnaire is an instrument for the collection of data, usually in written form, consisting of open and/or closed questions and other probes requiring a response from subjects". The questionnaire (respondents) provided the use of certain types of strategies and rate of the frequency of that strategy. Besides that information, there are many advantages of using questionnaire as Siriwan (2007) stated that the questionnaire can easily be administered to a large number of subjects and data compilation which are quite simple, and more notably, relevant to obtain accurate quantitative measures. In this study, the written questionnaire (see Appendix A) was used to search answers about the use of vocabulary memorizing strategies. In order to find the use and frequency of these strategies, the questionnaire included a five-scale likert measurement with the following measures: never, seldom, sometimes, usually, and always. The questionnaire included two parts. The first part consists of questions about the participants' demographic information such as gender, age, the program of study, and the period of learning English. Whereas the second part included 25 questions about the vocabulary memorization strategies, 7 questions for CML strategies, 9 questions for AIS strategies, 4 questions for RW strategies and 5 questions for EA strategies. For reliability, the questionnaire was translated into the Arabic language to be sure that the students understand all questions and they answer them. Before students answered the questions, the questions were explained orally and step by step to be sure that the students have a complete understanding of these questions and the results reflect the thought of students truthfully.

\subsection{Data Collection Procedures}

The procedures of collecting data of this study were divided into two stages and the data collection took place in May 2015. At the first stage, the researcher asked the head of the Language Center of UUM for permission to distribute the written questionnaires. In the next stage, the questionnaire was distributed to 65 Arab students in their classrooms and during the class or the lecture time. So, the researcher moved from one group to another to distribute the questionnaire. Before they answer the questions the researcher explained the purpose of the study, and an explanation was given to the students on how to complete the questionnaire. The questionnaire was translated to Arabic language, to be sure that the students have a complete understanding of the questions. So that the results reflect the thought of students truthfully. Figure 1 below shows these stages of data collecting.

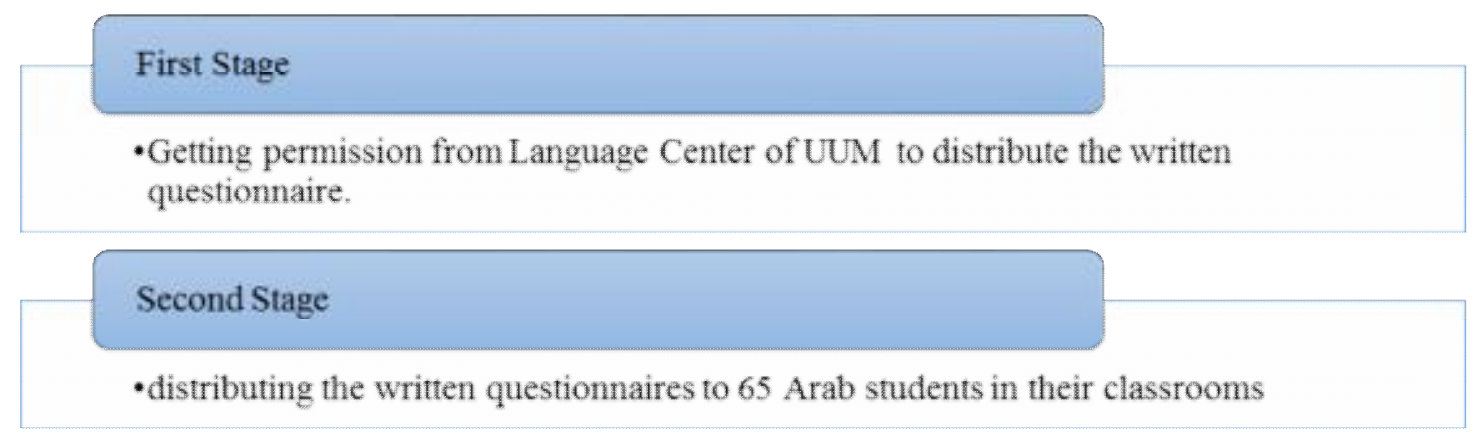

Figure 1. Procedures of Data Collection. 
Based on the previous researches and studies on language and vocabulary learning strategies, statistical analysis is a method used in analyzing data by the researchers. A statistical software SPSS (Statistical Package for the Social Sciences) which provides a convenient way of summarizing and interpreting the results was used in this study. Thus, a descriptive statistical analysis method was used in the study to handle the students' questionnaire data in order to find the percentages as well as the frequencies of the strategies. In addition, for the internal consistency reliability, value is calculated by SPSS software.

\section{Findings}

According to the scores system of mean classification of Oxford (1990), the frequency of students' strategy use is categorized as high, medium, and low. This system is organized by the respondent's frequency of use of the five-point likert scale in the questionnaire. According to the scores system of Oxford (1990), the scores counted between 1.0 and 2.4 on the five-point likert scale are regarded as a "low strategy use", which are those that are not generally used. Mean scores ranging between 2.5 and 3.4 are labeled as a "medium strategy use". The scores between 3.5 and 5.0 are regarded as a "high strategy use", which are those strategies that are generally used. The following table shows the overall vocabulary memorization strategies use by the Arab students.

Table 2. Descriptive Statistics for Overall Vocabulary Memorization Strategies Use

\begin{tabular}{ccc}
\hline Number of students & Mean score & SD \\
\hline 65 & 3.23 & .662 \\
\hline
\end{tabular}

Table 2 shows that 3.23 represent the overall mean score of the vocabulary memorization strategies used by the Arab students. According to Oxford's (1990) scoring system, the students of the current study were found to be medium strategy users. The findings demonstrate that it is crucial for lecturers of the Intensive English course to teach vocabulary strategies more thoroughly and more effectively. However, in terms of the internal consistency reliability coefficient, the alpha value of all categories was .733.

In the present study, the vocabulary memorization strategies have been grouped, as mentioned before, into four main categories. These categories are: 1) creating mental linkage (CML), 2) applying images and sounds (AIS), 3) reviewing well (RW), and 4) employing actions (EA). To locate the use of vocabulary memorization strategies, descriptive statistics including the mean and standard deviations of the main four categories were calculated. Table 5 shows the mean scores of the four categories of vocabulary memorization strategies.

Table 3. The Using of Vocabulary Memorization Strategies in the Four Categories

\begin{tabular}{cccccc}
\hline Category & N & Mean & SD & Rank & Frequently category \\
\hline RW & 65 & 3.52 & .632 & 1 & High use \\
CML & 65 & 3.39 & .566 & 2 & Medium use \\
AIS & 65 & 3.13 & .771 & 3 & Medium use \\
EA & 65 & 2.88 & .681 & 4 & Medium use \\
\hline
\end{tabular}

Table 3 shows the mean and frequency of the main categories of vocabulary memorization strategies. The most preferred strategies among the four strategies were reviewing well strategies (Mean=3.52, Std. Deviation=.632) at high usage level, followed by creating mental linkage (Mean=3.39, Std. Deviation=.566), applying images and sounds strategies (Mean=3.13, Std. Deviation=.771). Employing actions strategies were the least frequent strategies among all the four categories (Mean=2.88, Std. Deviation=.681) at the medium level of usage. However, review well strategies were high usage level, while other categories were at the medium level of usage. Low degree of strategy use was not found in any of the four categories of vocabulary memorization strategies. This result goes in line with previous research findings by Shooshtari, Hayati Samian and Khazaie (2013). They found that reviewing well category is among the most memorization categories used by the second group of Iranian students and they found also that Employing actions strategies came in the last rank with a medium use.

The next section provides further information on students' report of individual strategy use, when the students were asked about their use of strategies in vocabulary memorizing. There were 25 items which are a collection of four main categories of memorization strategies in vocabulary learning (CML, AIS, RW and EA). 
Table 4. Means of Vocabulary Memorization Strategies Used By the Arab Students in Descending Order.

\begin{tabular}{|c|c|c|c|c|}
\hline Categories \& abbreviated statements & & Rank & Mean & S.D \\
\hline \multicolumn{5}{|l|}{ High usage (M=3.5 or above) } \\
\hline RW Write words repeatedly to remember the words & (7) & 1 & 4.03 & .998 \\
\hline CML Memorize English words \& Arabic equivalents & (9) & 2 & 3.64 & 1.13 \\
\hline AIS Use after memorizing the words & $(24)$ & 3 & 3.64 & .855 \\
\hline CML Repeat words aloud to myself for memorizing & (6) & 4 & 3.61 & 1.11 \\
\hline CML Keep the vocabulary list of new words & (3) & 5 & 3.61 & 1.01 \\
\hline CML Make vocabulary lists of new words & (1) & 6 & 3.50 & 1.00 \\
\hline AIS Search synonyms \& antonyms for new words & $(25)$ & 7 & 3.50 & .925 \\
\hline \multicolumn{5}{|l|}{ Medium usage $(\mathrm{M}=2.5$ to 3.4$)$} \\
\hline AIS Imagine the word meaning to memorize & $(10)$ & 8 & 3.49 & 1.25 \\
\hline RW Focus on exercises of words before exams & $(23)$ & 9 & 3.49 & 1.03 \\
\hline EA Memorize set phrases and collocations & $(20)$ & 10 & 3.49 & 1.00 \\
\hline RW Review newly learned words & (19) & 11 & 3.38 & .878 \\
\hline CML Remember words by roots or affixes & $(17)$ & 12 & 3.38 & 1.26 \\
\hline AIS Combination sounds and images & (2) & 13 & 3.18 & 1.05 \\
\hline RW Do regular and structured reviews of new words & $(5)$ & 14 & 3.18 & .998 \\
\hline CML Connect a word to a personal experience & $(12)$ & 15 & 3.16 & .893 \\
\hline AIS Remember words that share similar letters & $(14)$ & 16 & 3.13 & 1.04 \\
\hline AIS Remember examples of word use in a context & (13) & 17 & 3.13 & .933 \\
\hline AIS Use semantic mapping to enlarge vocabulary & (4) & 18 & 3.01 & 1.36 \\
\hline CML Remember words by grouping into categories & $(18)$ & 19 & 2.89 & 1.06 \\
\hline EA Do oral spelling exercises of words with others & $(8)$ & 20 & 2.76 & .964 \\
\hline EA Recall words by pair checking with someone & $(11)$ & 21 & 2.75 & .952 \\
\hline EA Use cards with two sides of words \& meaning & $(21)$ & 22 & 2.72 & 1.29 \\
\hline EA Take the vocabulary cards wherever going & $(22)$ & 23 & 2.69 & 1.24 \\
\hline AIS Associate words with similar Arabic sound & $(16)$ & 24 & 2.64 & 1.21 \\
\hline \multicolumn{5}{|l|}{ Low usage $(\mathrm{M}=2.4$ or lower $)$} \\
\hline AIS Associate sounds of words with similar English & $(15)$ & 25 & 2.44 & 1.18 \\
\hline
\end{tabular}

Table 4 shows the vocabulary memorization strategies use by the 65 Arab postgraduate students in the Intensive English course in UUM. Based on the means and standard deviations, the vocabulary memorization strategies are listed in a descending order obtained by using descriptive statistics.

The results reveal that the mean score of all the vocabulary memorization strategies use ranged from 2.44 to 4.03 and the overall mean of the vocabulary memorization strategies was at a medium level of strategy use (mean=2.98). Table 6 indicates that RW strategies were ranked the highest, CML strategies was the second highest, followed by AIS strategies as the least preferred strategies by the Arab students in this sample. In detail, there were 7 of 25 statements $(28 \%)$ investigated as high usage, 17 of 25 statements (about $68 \%$ ) as medium usage, and only one item (about $4 \%$ ) as the low usage.

Among these strategies, the five most vocabulary memorization strategies frequently used by the Arab students in this study shown in table 7 .

Table 5. The Five Most Strategies Preferred by the Students

\begin{tabular}{lccc}
\hline \multicolumn{1}{c}{ Categories \& abbreviated statements } & Rank & Mean & S.D \\
\hline RW Write words repeatedly to remember the words & 1 & 4.03 & .998 \\
CML Memorize English words \& Arabic equivalents & 2 & 3.64 & 1.13 \\
AIS Use after memorizing the words & 3 & 3.64 & .855 \\
CML Repeat words aloud with myself for memorizing & 4 & 3.61 & 1.11 \\
CML Keep the vocabulary list of new words & 5 & 3.61 & 1.01 \\
\hline
\end{tabular}


Table 5 shows the five most frequent vocabulary memorization strategies used by the Arab students in this study. Three of the five most used strategies belong to the creating mental linkage strategies. The other two most used strategies among the Arab students belong to reviewing well as well as applying images and sounds strategies. The plausible explanation of finding some of these strategies like "Memorize English words \& Arabic equivalents" and "Keep the vocabulary list of new words" among the most popular strategies might be because they are the easiest and simplest way to learn a new word. Moreover, employing this strategy does not consume much time to find out the meaning of new words.

The following section shows the least frequently used strategies among 25 vocabulary memorization strategies used by the Arab students in the Intensive English course in UUM.

Table 6. The Five Least Preferred Strategies by the Students

\begin{tabular}{lccc}
\hline \multicolumn{1}{c}{ Categories \& abbreviated statements } & Rank & Mean & S.D \\
\hline AIS Associate sounds of words with similar English & 1 & 2.44 & 1.18 \\
AIS Associate words with similar Arabic sound & 2 & 2.64 & 1.21 \\
EA Take the vocabulary cards wherever going & 3 & 2.69 & 1.24 \\
EA Use cards with two sides of words \& meaning & 4 & 2.72 & 1.29 \\
EA Recall words by pair checking with someone & 5 & 2.75 & .952 \\
\hline
\end{tabular}

Table 6 shows that the least frequently used strategy among 25 vocabulary memorization strategies by the students in this study. The strategies mentioned above indicated that three of five least frequently used strategies belong to the employing action strategies. While the other two least strategies used belong to the applying images and sounds strategies. These strategies seem to be rarely used by the Arab students. Li (2004) and Sinhaneti and Kyaw (2012) also found that these strategies among the least preferred strategies used by the Chinese and Burmese students respectively. That means the Arab students do not prefer to use deep processing strategies.

\section{Discussions}

The findings of this study show that the Arab students were found to be medium strategy users. This mean score is consistent with some previous research studies; Sinhaneti and Kyaw (2012), Askar (2014). The findings demonstrate that it is crucial for lecturers of the Intensive English course to teach vocabulary strategies more thoroughly. It is found that in the Intensive English course, vocabulary memorization strategies were not effectively taught.

Regarding the use of vocabulary memorization strategies in the four categories, the results show that the Arab students in the Intensive English course use different types of vocabulary memorization strategies which are related to different main four categories of memory strategies. The results also show that the most preferred strategies among the four strategies were reviewing well strategies while Employing actions strategies were the least frequent strategies used by the Arab student in the Intensive English course. The possible reasons for using this category among the Arab students could be the nature of the program of the study and the instructions they received in the course. These instructions might encourage the second language use to include other aspects of vocabulary knowledge to strengthen the retention of the meaning at the time of examination. Another reason for this result indicated that the Arab students may are not familiar with some types of memorization strategies to employ, or they do not understand how to use these strategies and they need training to employ like these useful strategies. I addition to that, this study found that the Arab students used popular strategies in memorizing vocabulary that related to traditional method of teaching and learning English in the EFL context. According to Schmitt (2000), the Asian participants opted for simple vocabulary memorizing strategies. Thus, the result of this study might take into consideration the learning culture and the educational background is also taken into consideration.

On the other hand, the Arab students used repetition strategies to aid them in memorizing the word meaning and they preferred the easy strategies which do not require neither much of time nor much of effort on their part. Also they use easiest and simplest ways which do not need deep learning strategies to learn a new word. According to Nation (2001) the benefit of repetition is that it adds to the quality of knowledge as well as to the quantity of this knowledge. The possible assumption is made that since repetition is an effective technique in enhancing the vocabulary retention, the disregard of such strategies by the Arab students will result in vocabulary memorization.

In contrast to the most prefer strategies, the least strategies used by the Arab students show that they do not prefer to use deep processing strategies. Also the Arab students do not preferred to memorize vocabulary with someone or friends and they might be feeling embarrassed to memorize vocabulary with others, because they are afraid of not pronouncing or writing the word correctly. However, this study found that the Arab students prefer accuracy to fluency in vocabulary learning because they rely on some memorization strategies as an establishing foundation of accurate knowledge to develop language learning in the Intensive English course. 
In summary, the Arab students in the Intensive English course in UUM use different types of vocabulary memorization strategies and the educational and cultural background have an effect on the choice of types of memorization strategies in learning and memorizing vocabulary.

\subsection{Implications}

The following implications are based on the main results found in the present study:

The Arab students in the Intensive English course reported using different vocabulary memorization strategies, but they also neglected other memorization strategies. This further led to the fact that vocabulary is required to be taught explicitly in the course. Thus, this study suggests that the curriculum of the Intensive English course needs to take into consideration the learning and memorizing strategies explicitly. Taking these considerations in the effective way could be useful for the lecturers and the students alike. This can be achieved with the support of the lecturers and the students. The lecturers support through bringing their learners ${ }^{\text {ee }}$ awareness by employing more effective strategies to improve their vocabulary learning. Also, training learners by using various strategies would probably lead to better and independent second language learners in the language learning process. To do this, teachers need to be familiar with different kinds of vocabulary memorization strategies at first. Then, they are required to train their learners with different learning strategies. On the other hand, the students are encouraged to generate more effective strategies which facilitate the task of learning and memorizing vocabulary. These strategies should involve activities of listening, speaking, and writing the target words as well as reading texts. Students are also encouraged to use the learned words in communication through practice with useful activities inside and outside the classroom.

\subsection{Recommendations}

This study found that the memorization strategies play an integral role in vocabulary learning among the Arab students. Therefore, the findings suggest that there might be some reasons to explain the use of memorization strategies. According to Oxford (1990), there are eight factors to be considered, influencing the choice of second language learning strategies: (1) motivation; (2) gender; (3) cultural background; (4) attitude and beliefs; (5) type of task; (6) age; (7) learning style; and (8) tolerance of ambiguity. The eight factors mentioned above can serve as food for thought in the study of the learning strategies used by the Arab EFL learners. The present study was mainly involved with three of the aspects above - cultural background, learning style, and attitudes and beliefs. Therefore, the other factors affecting the Arab EFL learners need to be considered in the further study. This study also suggests further studies to investigate the preference of vocabulary memorization strategies among the Arab learners in other universities in Malaysia and make a comparison of the results as the lecturers of some universities may have great impact on participants ${ }^{\text {ee }}$ motivation to learn English as a foreign language.

\section{Conclusion}

The present study indicated some direct implications which are found in the findings, the cultural and educational background of the Arab students and Intensive English course examination system which might be constructively affected by this study. However, the current study suggested some areas that would be more beneficial to investigate in further researches such as examining more factors that might affect using memorization strategies, investigate vocabulary memorization strategies preference by the Arab students in other universities in Malaysia (more than one university) and compare the results. This study had highlighted the role played by the vocabulary memorization strategies in learning the English vocabulary. Especially, it suggested that the investigation of the present study might have a favorable impact on memorization strategies in learning the English language. Therefore, the study recommends that the approaches could be replicated in other universities or in other EFL countries.

\section{References}

Asgari, A., \& Mustapha, G. B. (2011). The type of vocabulary learning strategies used by ESL students in University Putra Malaysia. English Language Teaching, 4(2), 84-90.

Askar, w. A. (2014). A survey on The Use of Vocabulary Learning Strategies By ELT and ELL Students of Duhok University in Northern Iraq.Unpublishedd master's thesis, Cyprus. Turkey.

Cameron, L. (2005). Teaching languages to young learners. U.K.: Cambridge University Press.

Catalan, R. M. J. (2003). Sex differences in L2 vocabulary learning strategies. International Journal of Applied Linguistics, 13(1), 54-77.

Cohen, A. D. (1998). Strategies in learning and using a second language. London, UK: Longman.

Craik, F. I. M., \& Lockhart, R. S. (1972). Levels of processing: A framework for memory research. Journal of Verbal Learning and Verbal Behavior, 11, 671-684.

Craik, F. I. M., \& Tulving, E. (1975). Depth of processing and the retention of words in episodic memory. Journal of Experimental Psychology (104), 268-284.

Ellis, R. (1994). The study of second language acquisition. Oxford: Oxford University Press.

Gairns, R. \& Redman (1986). Working with Words - A Guide to Teaching and Learning Vocabulary. Cambridge: Cambridge University Press. 
Gardner, D. (2013). Exploring vocabulary: Language in action. Routledge.

Ghorbani, M. R., \& Riabi, N. K. (2011). The impact of memory strategy instruction on learners' EFL vocabulary retention. Theory and Practice in Language Studies, 1(9), 1222-1226.

Graves, K. (2000). Designing language courses: A guide for teachers. Boston: Heinle \& Heinle Publishers.

Gu, P. Y. (2003). Vocabulary learning in a second language: Person, task, context and strategies. TESL-EJ, 7(2), 1-25.

Gu, Y., \& Johnson, R. K. (1996). Vocabulary learning strategies and language learning outcomes. Language Learning $46(4), 643-679$.

Hatch, E., \& Brown, C. (1995). Vocabulary, semantics, and language education, Cambridge: Cambridge University Press.

Hedge, T. (2000). Teaching and learning in the language classroom. Oxford: Oxford University Press.

Heidari, F. L., Karimi, F., \& Imani, A. (2012). Vocabulary learning strategy instruction: Its impact on English for specific purpose vocabulary achievement and reading comprehension. Middle-East Journal of Scientific Research, $12(11), 1488-1496$.

Lee, K. R., \& Oxford, R. (2008). Understanding EFL learners' strategy use and strategy awareness. Asian EFL Journal, $10(1), 7-32$.

Li, X. (2004). An analysis of Chinese EFL learners' beliefs about the role of rote learning in vocabulary learning strategies. Doctoral dissertation, University of Sunderland.

Ma, Q. (2009). Second language vocabulary acquisition, (Vol. 79). Peter Lang.

Nation, I.S.P. (2001). Learning vocabulary in another language. London: Cambridge University.

Nemati, A. (2009). Memory vocabulary learning strategies and long-term retention. International Journal of Vocational and Technical Education, 1(2), 14-24.

Nunan, D. (1992). Research Methods in Language Learning. Cambridge: Cambridge University Press.

Oanh, D. T. H., \& Hien, N. T. (2006). Memorization and EFL students' strategies at university level in Vietnam. TESLEJ, 10(2), 1-21.

O'Malley, J., \& Chamot, A. (1990). Learning strategies in second language acquisition. Cambridge: Cambridge University Press.

O’Malley, J. M., Chamot, A.U., Stewner-Manzanares, G., Russo, R.P. \& Kupper, L. (1985). Learning Strategy Applications with Students of English as a Second Language. TESOL Quarterly, 19,pp. 557-584.

Oxford, R, (1990). Language learning strategies: What every teacher should know. New York: Newbury House.

Oxford, R. L. (2003). Language learning styles and strategies: An overview. GALA. Retrieved December 20, 2014, from http://web.ntpu.edu.tw/ language/ workshop/ read2.pdf

Purpura, J. E. (1994). The Role of Learner Strategies in Language Learning and Testing. Paper given at the Thai TESOL Conference, Bangkok, January, 1994.

Read, J. (2000). Assessing vocabulary. Cambridge: Cambridge University Press.

Rubin, J. (1981). Study of cognitive Processes in Second Language Learning. Applied Linguistics, 2, 117-131.

Schmitt, N. (1997). Vocabulary learning strategies. New York: Cambridge University Press.

Schmitt, N. (2000). Vocabulary in language teaching. New York: Cambridge University Press.

Sinhaneti, K., \& Kyaw, E. K. (2012). A study of the role of rote learning in vocabulary learning strategies of Burmese students. Online Submission.

Siriwan, M. (2007). English vocabulary learning strategies employed by Rajabhat university students. Unpublished Doctoral Dissertation, Suranaree University of Technology, Thailand.

Stern, H. (1983). Fundamental Concepts of Language Teaching. Oxford: Oxford University Press.

Tarone, E. (1981). Some thoughts on the notion of communication strategy. TESOL Quarterly, 15, 285-295.

Yang, W., \& Dai, W. (2011). Rote memorization of vocabulary and vocabulary development. Canadian Center of Science and Education, 4(4), 61-64.

Yusuf, M. (2010). Memorization as a learning style: A balance approach to academic excellence. OIDA International Journal of Sustainable Development, 1(6), 49-58.

Webb, S. (2008). Receptive and productive vocabulary sizes of L2 learners. Studies in Second Language Acquisition, 30, 79-95.

Wenden, A., \& Rubin, J. (1987). Learner strategies in language learning. New York: Prentice Hall. pp. 15-30. 


\section{APPENDIX A: THE VOCABULARY MEMORIZATION STRATEGIES QUESTIONNAIRE}

Please answer the questions first, before you continue on to the following questionnaire.

Part I : The background information
1- Age:
2- Gender: male / female (circle one)
3- Program of the study:
4- Period of learning English:

The following list is a list of vocabulary memorization strategies, means the methods by which you learn vocabulary. I would like to know what you actually do, NOT. I would like you to indicate how often you have used a certain strategy in the intensive English course, irrespective of the skills (i, e. listening, reading, speaking, and writing). Please indicate the frequency of the strategies you use.

Part II : The content of the questionnaire

1- I make vocabulary lists of new words that I meet. (1)

Never seldom sometimes usually always

2- I remember new words by combination sounds and images. (2)

Never seldom sometimes usually always

3- I keep the vocabulary lists of new words that I make. (1)

Never seldom sometimes usually always

4- I use semantic mapping to enlarge vocabulary. (2)

Never seldom sometimes usually always

5- I make a regular and structured reviews of new words I have memorized. (3)

Never seldom sometimes usually always

6- When I try to memorize a word, I repeat it aloud to myself. (1)

Never seldom sometimes usually always

7- When I try to remember a word, I write it repeatedly. (3)

Never seldom sometimes usually always

8- I do oral spelling exercises with my friends whose English level is at a similar level of mine.4

Never seldom sometimes usually always

9- I write both the English new words and their Arabic equivalents repeatedly in order to remember them. (1)

Never seldom sometimes usually always

10- I image the word meaning. (2)

Never seldom sometimes usually always

11- I recall the words by pair checking with someone else. (4)

Never seldom sometimes usually always

12- I connect a word to a personal experience. (1)

Never seldom sometimes usually always

13- I memorize examples in some context when using the words. (2)

Never seldom sometimes usually always

14- I remember a group of new words that share similar letters in spelling.(e.g. big, bag,bug).(2)

Never seldom sometimes usually always

15- I associate the sound of the word with the same sound of a similar word in English. (2)

$$
\text { Never seldom sometimes usually always }
$$

16- I associate new words with words that sound similar in Arabic. (2)

$$
\text { Never seldom sometimes usually always }
$$


17- I break up the word into components (e.g.roots, prefixes). (1)

Never seldom sometimes usually always

18- I group words into categories (e.g., animals, utensils, vegetables, etc.). (1)

$$
\text { Never seldom sometimes usually always }
$$

19- I review newly learned words. (3)

Never seldom sometimes usually always

20- I pay attention to set phrases and collocations that go with a word. (4)

$$
\text { Never seldom sometimes usually always }
$$

21- I write the new words on one side of a card and the definition on the other side. (4)

$$
\text { Never seldom sometimes usually always }
$$

22- I make vocabulary cards and take them with me wherever I go. (4)

$$
\text { Never seldom sometimes usually always }
$$

23- I focus my attention on completing vocabulary exercises repeatedly before exams. (3)

$$
\text { Never seldom sometimes usually always }
$$

24- I can use words correctly and efficiently after memorizing them. (2)

$$
\text { Never seldom sometimes usually always }
$$

25- When I meet a new word, I search in my memory and see if I have any synonyms and antonyms in my memory stock. (2)

$$
\text { Never seldom } \quad \text { sometimes asually always }
$$

Please write any other strategies you have used that are not written above, if any. Thank you very much for your cooperation. I will use your answers as effectively as I can.

Researcher: Fouad Hussein Ali

University: UUM

Email: fhn58@yahoo.com

Phone number: 01136540345

\section{APPENDIX A: THE VOCABULARY MEMORIZATION STRATEGIES QUESTIONNAIRE (ARABIC VERSION)}

$$
\begin{aligned}
& \text { عزيزي الطالب }
\end{aligned}
$$

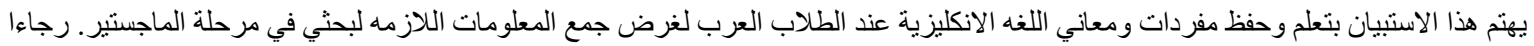

$$
\begin{aligned}
& \text { اجب الاسئله بصورة تامة ولكن قبل ان تبدا بالاجابه على الاسئله, مهم جدا ان تجيب على الاسئله الثخصيه في الجزء الهُ الاول من الاستبيان. }
\end{aligned}
$$

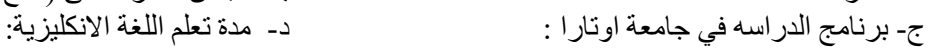

$$
\begin{aligned}
& \text { القائمه التاليه هي قائمه ستر اتيجات تعلم وحفظ المفردات او معاني الكلمات, يعني الاساليب و الطرق التي تلتبعها في تعلم وحفظ المفردات. }
\end{aligned}
$$

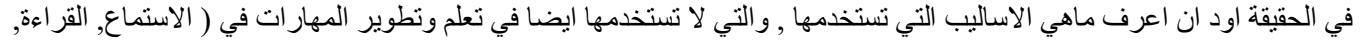

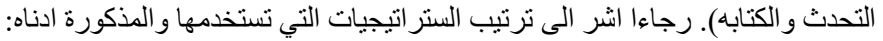

$$
\begin{aligned}
& \text { الجزء الثاني من الاستبيان: }
\end{aligned}
$$

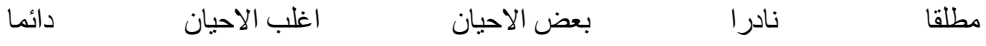




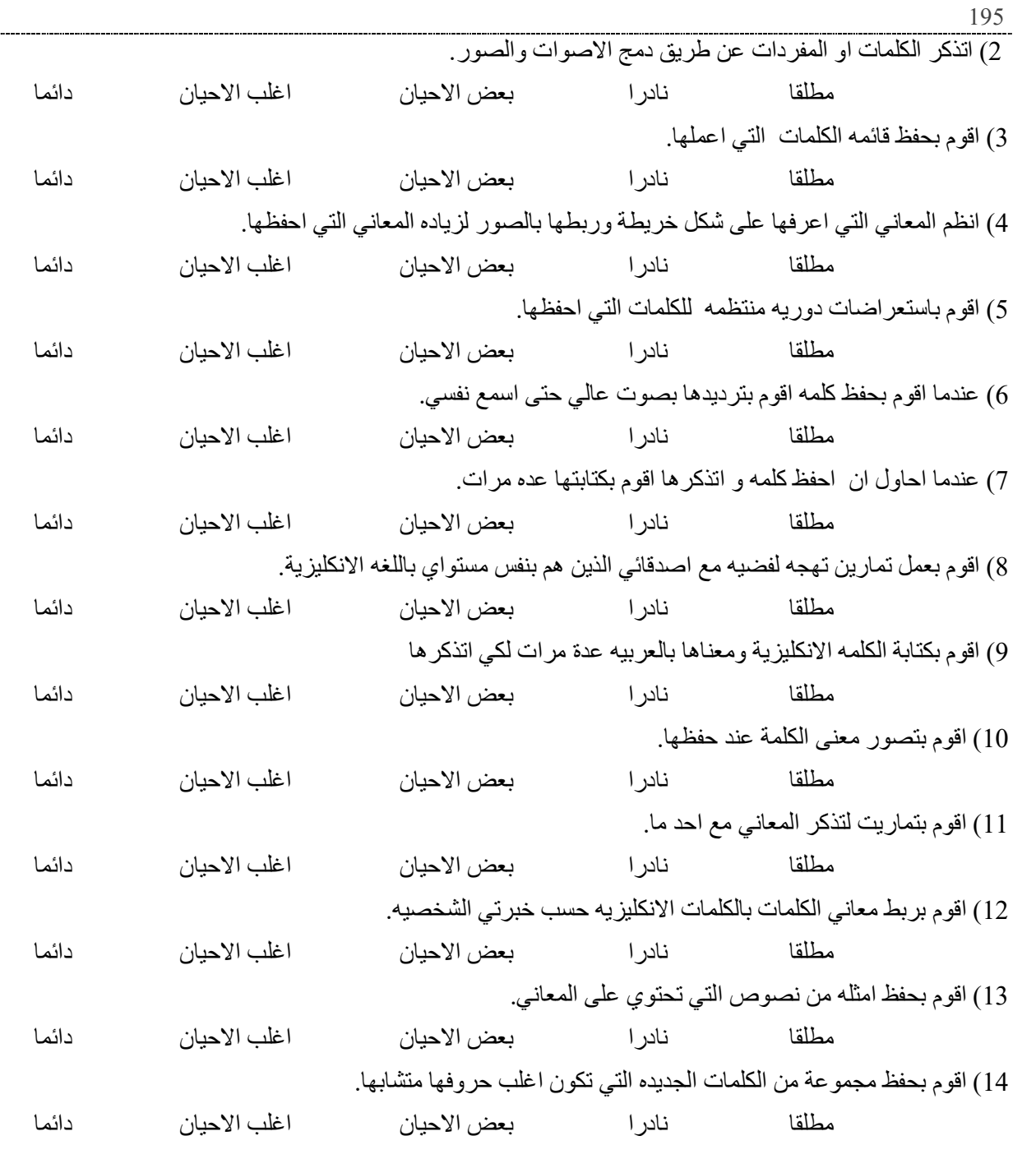
2) 195

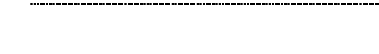$$
\text { 15) اقوم بربط صوت الكلمات العربيه مع الكلمات التي تحمل نفس الصوت في الانكليزيه. }
$$

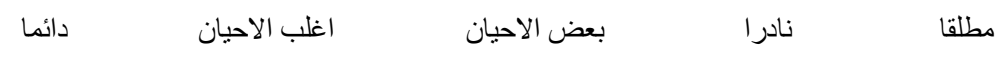$$
\text { 16) اقوم بربط الكلمات الجديده التي تشبه في لفظها الكلمات العربيه. }
$$$$
\text { 19) } 19 \text { اقوم باستعر اض الكلمات الجديده التي حفظتها. }
$$

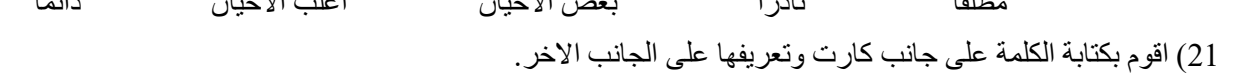

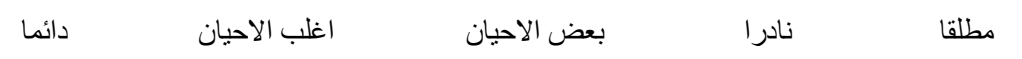

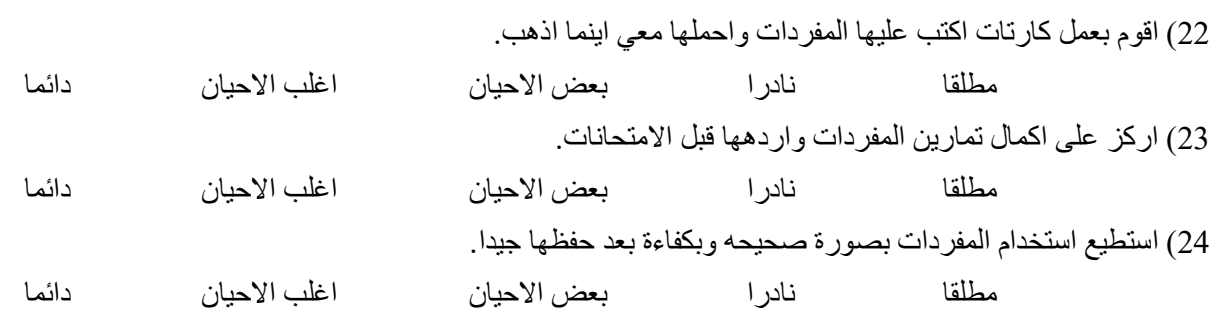


25) عندما او اجه كلمات جديدة ابحت في ذاكرتي عن مر ادف او معاكس لها.

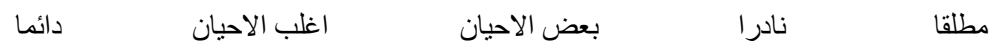

رجاءا اكتب اي ستر اتيجيه او طريقه اخرى تستخدمها في تعلم وحفظ المعاني غير الطرق و الاساليب المذكوره اعلاه ان وجدت.

اشكركم جدا و اشكر جهو دكم وتعاونكم معي وسوف استخدم اجوبتكم بدقه وبفاعليه لتحقيق الاهداف المرجوه.

الباحث: فؤاد حسين علي

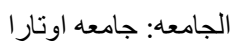

الاميل: fhn58@yahoo.com 